\title{
O financiamento público estadual do esporte no Estado de Goiás ${ }^{1}$
}

\section{State public funding of sports in the State of Goiás}

\section{La financiación pública estadual del deporte en el Estado de Goiás}

\author{
iD Oromar Augusto dos Santos Nascimento \\ Universidade de Brasília, Brasília, Distrito Federal, Brasil. \\ oromar.augusto@gmail.com \\ iD? Fernando Resende Cavalcante \\ Universidade de Brasília, Brasília, Distrito Federal, Brasil.
} fernandorcavalcante@hotmail.com

iD Pedro Fernando Avalone de Athayde Universidade de Brasília (UnB), Brasília, Distrito Federal, Brasil. pedroavalone@gmail.com

iD Ari Lazzarotti Filho Universidade Federal de Goiás, Goiânia, Goiás, Brasil. arilazzarotti@gmail.com

Resumo: Este estudo teve como objetivo mapear os gastos do Governo do Estado de Goiás com o esporte nos anos de 2011 a 2017. Realizou-se um levantamento dos dados disponíveis no Portal Goiás Transparente, analisando-os com base na metodologia de avaliação de políticas sociais proposta por Ivanete Boschetti. Os resultados evidenciaram que mais de $\mathrm{R} \$ 195$ milhões foram gastos com esporte no período, com continuidade de programas esportivos e significativa parcela de recursos direcionados à construção/manutenção/reforma de espaços e equipamentos esportivos. Concluiu-se que no período analisado o Estado de Goiás destinou

10 presente trabalho foi realizado com apoio da Coordenação de Aperfeiçoamento de Pessoal de Nível Superior - Brasil (CAPES) - Código de Financiamento 001. 
quantias proporcionalmente baixas ao esporte, distribuídas de forma instável no decorrer dos anos.

Palavras-chave: Financiamento Governamental. Política. Esportes. Goiás

Abstract: This study aimed to map the expenditures of the State of Goiás Government with the sport in the years 2011 to 2017. A survey of the data available in the Goiás Transparente Portal was carried out, analyzing them based on the methodology of evaluation of social policies proposed by Ivanete Boschetti. The results showed that over R $\$ 195$ million were spent on sports in the period, with a continuity of sports programs and a significant portion of resources directed to the construction / maintenance / remodeling of sports spaces and equipment. It was concluded that during the analyzed period, the State of Goiás allocated amounts proportionally low to the sport and distributed in an unstable manner over the years.

Keywords: Financing, Government. Politics. Sports. Goiás

Resumen: Este estudio tuvo como objetivo mapear los gastos del Gobierno del Estado de Goiás con el deporte, en los años 2011 a 2017. Se realizó un levantamiento de los datos disponibles en el Portal Goiás Transparente, analizándolos a partir de la metodología de evaluación de políticas sociales propuesta por Ivanete Boschetti. Los resultados evidenciaron que más de $\mathrm{R}$ \$ 195 millones fueron gastados con deporte en el período, con continuidad de programas deportivos y significativa parte de recursos dirigidos a la construcción / mantenimiento / reforma de espacios y equipamientos desportivos. Se concluyó que en el período analizado el Estado de Goiás destinó cantidades proporcionalmente bajas al deporte y distribuido de forma inestable a lo largo de los años.

Palabras clave: Financiación Gubernamental. Política. Deportes. Goiás.

Submetido em: 11-02-2019

Aceito em: 21-05-2019 
O financiamento público estadual do esporte no Estado de Goiás

Oromar Augusto dos Santos Nascimento • Fernando Resende Cavalcante • Pedro Fernando Avalone de Athayde • Ari Lazzarotti Filho

\section{Introdução}

O tema deste estudo é o financiamento público estadual das ações direcionadas ao esporte no Estado de Goiás nos anos de 2011 a 2017. Esse recorte temporal corresponde ao terceiro e a três quartos do quarto mandato do Governador Marconi Perillo (PSDB), eleito em 2010 para seu terceiro mandato e reeleito em 2014, que permitiu uma avaliação dos direcionamentos do montante destinado às políticas de esporte do Estado de Goiás.

O financiamento é uma das dimensões da avaliação das políticas sociais proposta por Boschetti (2009). A autora indica que analisar e avaliar uma política social fornece indicativos de sua importância nas ações do Estado, bem como permite acompanhar os interesses que se desenvolvem atrelados a essas políticas. Esta análise não pode ser feita sem as devidas relações com aspectos centrais da política econômica e sem a definição do papel do Estado na economia (BOSCHETTI, 2009).

Nesta perspectiva, a autora indica a avaliação do financiamento das políticas sociais a partir de três elementos, as fontes, a direção e a magnitude dos gastos. As fontes do financiamento revelam de onde o recurso destinado às políticas é proveniente, o que permite estabelecer relações sobre quem realmente as sustenta (trabalhadores, empresários, capital estrangeiro, dentre outros). A direção dos gastos possibilita analisar a distribuição dos recursos das políticas, dos programas e projetos, além da distribuição regional dos mesmos. A magnitude dos gastos demonstra o volume financeiro voltado para as políticas e programas, acompanhando indicadores de crescimento, decrescimento e estabelecendo padrões de gastos. Neste elemento, é importante traçar comparativos entre os recursos aprovados e os efetivamente gastos, pois indicam com maior fidelidade a importância de determinada política, programa, ação, no planejamento e execução estatal (BOSCHETTI, 2009).

A literatura veiculada em periódicos brasileiros da Educação Física tem contemplado estudos sobre as políticas de esporte 
O financiamento público estadual do esporte no Estado de Goiás

Oromar Augusto dos Santos Nascimento • Fernando Resende Cavalcante • Pedro Fernando Avalone de Athayde • Ari Lazzarotti Filho

(QUINAUD; ALMEIDA, 2018). Na esfera federal, a literatura científica aponta uma predominância de investimentos destinados ao esporte de rendimento e espetáculo por meio do fomento de bolsas para atletas, desonerações fiscais para compras de equipamentos esportivos, aumento dos repasses ao Comitê Olímpico Brasileiro $(\mathrm{COB})^{2}$ e Federações Esportivas, construção de equipamentos e infraestrutura para receber os eventos, em detrimento dos investimentos voltados para a democratização do acesso ao esporte, entendidos através de programas como o PELC e o PST (TEIXEIRA et al., 2017; TEIXEIRA, MATIAS; MASCARENHAS, 2017; ATHAYDE et al., 2015).

No recorte temporal deste estudo, de 2011 até 2017, as políticas esportivas no Brasil passaram por um período único, pois o país sediou grandes eventos esportivos, como os Jogos Mundiais Militares no Rio de Janeiro (2011), a Copa das Confederações (2013), Copa do Mundo FIFA (2014), e os Jogos Olímpicos do Rio de Janeiro (2016). Esse ciclo de megaeventos esportivos no país teve íntima relação com a proposta neodesenvolvimentista ${ }^{3}$ dos governos Lula e Dilma, pois coube ao Estado alinhar e agregar as estratégias para o desenvolvimento dos eventos, além de financiar grande parte das obras necessárias para sua realização e captar investimentos que garantissem rentabilidade de capital (MASCARENHAS, 2012).

Esse ciclo experimentado pelo esporte no Brasil não ficou restrito aos megaeventos, mas permearam outros níveis de desenvolvimento e experiência com o esporte. Ações destinadas à construção de espaços e equipamentos comunitários de esporte e lazer (Programa Esporte e Lazer da Cidade), programas ligados à promoção do esporte educacional e à inclusão de jovens em vulnerabilidade social (Programa Segundo Tempo - PST) são exemplos de políticas esportivas em nível federal que criaram ações rumo a uma democratização a seu acesso.

\footnotetext{
2 Segundo Athayde (2015), este repasse foi regulamentado pela Lei Agnelo/Piva (Lei $n^{\circ} 10.264$, de julho de 2001), sancionada no Governo Fernando Henrique Cardoso (1995 - 2003), anterior ao governo Lula (2003-2011) e ao ciclo dos megaeventos.

3 Neodesenvolvimentismo foi, em linhas gerais, segundo Boito Junior (2012), uma frente política no Brasil do século XXI, em que buscou-se o crescimento econômico do país alinhado aos programas de transferência de renda, ao fortalecimento das empresas nacionais com subsídio estatal e às políticas de investimento em infraestrutura por parte do Estado, sem romper com o ideal neoliberal.
} 
O financiamento público estadual do esporte no Estado de Goiás

Oromar Augusto dos Santos Nascimento • Fernando Resende Cavalcante • Pedro Fernando Avalone de Athayde • Ari Lazzarotti Filho

Athayde (2015) diagnosticou que o Programa Segundo Tempo, em seu projeto inicial e modelo conceitual, apresentava evidências de um entendimento de esporte como direito do cidadão. Entretanto, ao se analisar os recursos investidos no programa, é perceptível que essa não era a prioridade do financiamento público destinado ao esporte, apesar de seu potencial de democratização do acesso à prática esportiva. Considerando os gastos com a função Desporto e Lazer entre 2004 e 2010, verificou-se que o investimento com o Programa Segundo Tempo correspondeu ao montante de $\mathrm{R} \$ 1.941$ Bilhões, enquanto os gastos previstos com a Copa do Mundo 2014 e os Jogos do Rio 2016 giraram em torno de $\mathrm{R} \$ 23.571$ bilhões e $\mathrm{R} \$ 12.518$ bilhões, respectivamente.

Além desses fatores, a própria configuração da política brasileira prevê repasses da União para os Estados, além de emendas parlamentares e demais mecanismos de distribuição de recursos. Portanto, para a compreensão da maneira como se efetivaram as ações mencionadas anteriormente, entender como esse ciclo da política esportiva (e aspectos do ciclo econômico) brasileira se materializou, pode-se observar os estudos regionais e estaduais.

No que tange aos Estados brasileiros, percebe-se que os direcionamentos da política esportiva seguiram elementos norteadores federais, ainda que os estudos apontem obstáculos na captação de recursos em razão da dificuldade de construção de uma política esportiva nacional que efetivasse as ações das diferentes esferas do poder executivo sobre o esporte (DINIZ; SILVA, 2016). Starepravo et al. (2010) estudaram o esporte universitário brasileiro, com ênfase na Federação Paranaense de Desporto Universitário, e identificaram quatro fases de organização histórica do esporte universitário no Brasil, em todas o Estado aparece como seu principal agente organizador e financiador.

Furtado et al. (2016) analisaram a distribuição de recursos financeiros do Fundo Estadual de Incentivo ao Esporte de Santa Catarina (FUNDESPORTE), para a Secretaria Estadual de Turismo, Cultura e Esporte de Santa Catarina, e perceberam que os repasses foram, em grande parte, direcionados para o esporte de alto 
O financiamento público estadual do esporte no Estado de Goiás Oromar Augusto dos Santos Nascimento • Fernando Resende Cavalcante • Pedro Fernando Avalone de Athayde • Ari Lazzarotti Filho

rendimento, especificamente para o financiamento de eventos de grande porte. Esses achados são corroborados por Quinaud e Almeida (2018), que estudaram os repasses do FUNDESPORTE direcionados para a mesorregião de Florianópolis (SC) e detectaram significativos montantes para a infraestrutura esportiva e a prioridade do esporte de alto rendimento.

O Estado de Goiás, por sua vez, não fez parte do mapa dos eventos. Na Copa do Mundo FIFA 2014, a capital (Goiânia) não foi escolhida como sede de nenhuma das partidas entre seleções, apesar de ter recebido jogos da seleção brasileira de futebol no período preparatório para o referido evento. O que não implica a inexistência de políticas direcionadas ao esporte no referido Estado.

Para auxiliar na compreensão desse cenário, esta pesquisa teve como objetivo mapear o financiamento público estadual das políticas de esporte no Estado de Goiás, nos anos de 2011 a 2017, a partir da Execução Orçamentária publicada no portal Goiás Transparente. Este estudo justifica-se pela necessidade de acompanhar e avaliar os gastos públicos, especialmente aqueles destinados ao esporte, fenômeno que dispõe de significativo prestígio e relevância social.

\section{Metodologia}

Este estudo se caracteriza como uma pesquisa social de caráter qualitativo, com elementos quantitativos que representam os valores relativos ao financiamento. Segundo Minayo (2009), a pesquisa qualitativa se debruça em questões que não podem ser caracterizadas como variáveis em uma análise, pois se trata de motivações, significados, valores que estão presentes no fenômeno estudado.

Os dados do financiamento foram coletados do dia 22 de novembro de 2017 e atualizados no dia 24 de outubro de 2018, 
O financiamento público estadual do esporte no Estado de Goiás

Oromar Augusto dos Santos Nascimento • Fernando Resende Cavalcante • Pedro Fernando Avalone de Athayde • Ari Lazzarotti Filho

no Portal Goiás Transparente4. Trata-se dos dados relativos à Execução Orçamentária dos anos de 2011 a 2017, disponíveis no referido portal, a partir da função "Desporto e Lazer", e programas e ações destinados ao esporte. Entende-se função a partir do art. $1^{\circ}$ da portaria n. 42, de 14 de abril de 1999, como "o maior nível de agregação das diversas áreas de despesa que competem ao setor público" (BRASIL, 1999, p. 01). Os valores encontrados foram corrigidos pelo Índice Geral de Preços - Disponibilidade Interna (IGPDI)5, com o auxílio da ferramenta "Calculadora do cidadão"6.

A seleção do material de análise seguiu as seguintes etapas: I - Acesso ao portal Goiás Transparente; II - Na aba "funcional", seleção do período estudado, 2011-2017, seleção da Função "Desporto e Lazer"; III - Na aba "Programa/ação", selecionou-se o período 2011-2017; IV- Exportaram-se os dados recuperados para uma pasta de trabalho do Excel, reorganizando-os para exibição dos montantes que seguem. V - Buscou-se nos Planos Plurianuais (PPA) de 2009-2011, 2012-2015 e 2016-2019 a identificação dos Programas e Ações destinadas ao esporte no período, para auxiliar na compreensão dos dados encontrados na etapa III.

Os dados recuperados nas cinco etapas foram analisados com base na metodologia para análise e avaliação de políticas sociais proposta por Boschetti (2009), pela exploração da magnitude e a direção dos gastos que compõem dois dos três aspectos do financiamento. Optou-se por não abordar um terceiro aspecto do financiamento, o das fontes dos recursos, pois trata-se de um tema denso e que iria extrapolar os limites deste trabalho.

\footnotetext{
40 portal Goiás Transparente é uma ferramenta de acompanhamento e controle dos gastos estatais, disponível em: http:// www.transparencia.go.gov.br/portaldatransparencia/. Acesso em: 10 abr. 2020.

5 O IGP-DI é uma versão do IGP, que mede a evolução dos preços com dados coletados entre o primeiro e último dia do mês de referência. Disponível em: https://www.portalbrasil.net/igp/. Acesso em: jul. 2020.

6 Disponível em: https://goo.gl/7TuAw3. Acesso em: 10 abr. 2020.
} 
O financiamento público estadual do esporte no Estado de Goiás

Oromar Augusto dos Santos Nascimento • Fernando Resende Cavalcante • Pedro Fernando Avalone de Athayde • Ari Lazzarotti Filho

\section{Resultados e discussão}

Os resultados estão expostos em dois blocos, todos referentes ao recorte temporal do estudo, os anos de 2011 a 2017. No primeiro consta a magnitude dos gastos destinados à função Desporto e Lazer, relacionados com o Produto Interno Bruto (PIB) e o Orçamento Fiscal de Seguridade Social (OFSS). No segundo consta o direcionamento dos gastos, expostos a partir dos programas e ações relacionados ao esporte no Estado de Goiás.

\section{Magnitude dos gastos}

A Função Desporto e Lazer recebeu $\mathrm{R} \$ 195.443 .809,07$ no período de 2011 a 2017. Observou-se pouca variação entre os valores empenhados e pagos, e grande variação na distribuição dos recursos, conforme indicado na Figura 1.

Figura 1 - Valores destinados à Função Desporto e Lazer no período de 2011 a 2017

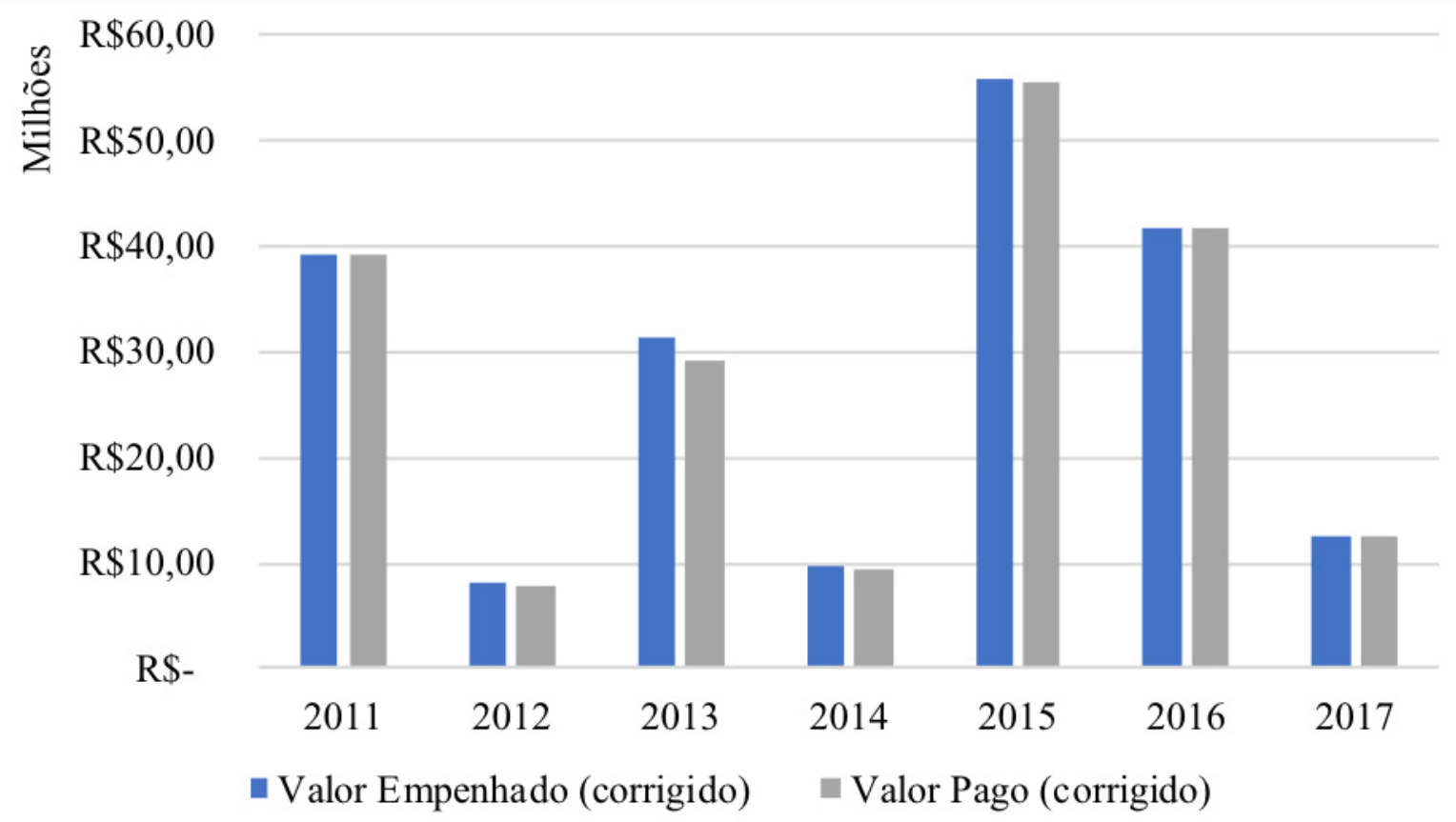

Fonte: Dados da pesquisa 
O financiamento público estadual do esporte no Estado de Goiás

Oromar Augusto dos Santos Nascimento • Fernando Resende Cavalcante • Pedro Fernando Avalone de Athayde • Ari Lazzarotti Filho

Percebeu-se que não há uma continuidade nos valores, que oscilam no período estudado atingindo o valor mais baixo no ano de 2012 , com $\mathrm{R} \$ 7,85$ milhões pagos, e no ano de 2015 atinge seu valor mais alto, com $\mathrm{R} \$ 55,44$ milhões. Em 2016 registrou-se o segundo maior gasto, $\mathrm{R} \$ 41,73$ milhões, seguido de queda em 2017, $\mathrm{R} \$ 12,44$ milhões. Outra característica é a aproximação entre valores empenhados e pagos, o que nos possibilita associar a uma excelente execução orçamentária, característica distinta daquela observada por Athayde et al. (2015) no âmbito federal, sobretudo no Programa Segundo Tempo e no Programa Esporte e Lazer da Cidade. Seria enriquecedor poder analisar também os valores previstos, mas estes não se encontravam disponíveis nos dados consultados.

A participação da função Desporto e Lazer nos gastos do Governo Estadual pode ser visualizada na Figura 2. Nela está exposta a participação da Função Desporto e Lazer no Orçamento Fiscal de Seguridade Social a partir dos valores pagos. Percebeuse que o orçamento teve um crescente entre 2011 e 2014, ano em que atingiu o valor máximo no período, com $\mathrm{R} \$ 22,2$ bilhões pagos; em seguida inicia num movimento descendente, atingindo valores próximos a $\mathrm{R} \$ 18,4$ bilhões pagos em 2016 , e novo crescimento em 2017, com $R \$ 20,9$ bilhões pagos.

Esse comportamento não foi observado no que diz respeito à função Desporto e Lazer, pois não houve um padrão dos gastos destinados à referida função, mas oscilações que não tiveram necessariamente relações com o movimento do Orçamento Fiscal de Seguridade Social. Em 2014, por exemplo, houve o maior valor do Orçamento Fiscal de Seguridade Social e o segundo menor direcionamento na Função Desporto e Lazer, ocasionando a participação percentual da referida função, cerca de 0,04\% do referido orçamento. 
O financiamento público estadual do esporte no Estado de Goiás

Oromar Augusto dos Santos Nascimento • Fernando Resende Cavalcante • Pedro Fernando Avalone de Athayde • Ari Lazzarotti Filho

\section{Figura 2 - Participação da Função Desporto e Lazer no Orçamento Fiscal de Seguridade Social}

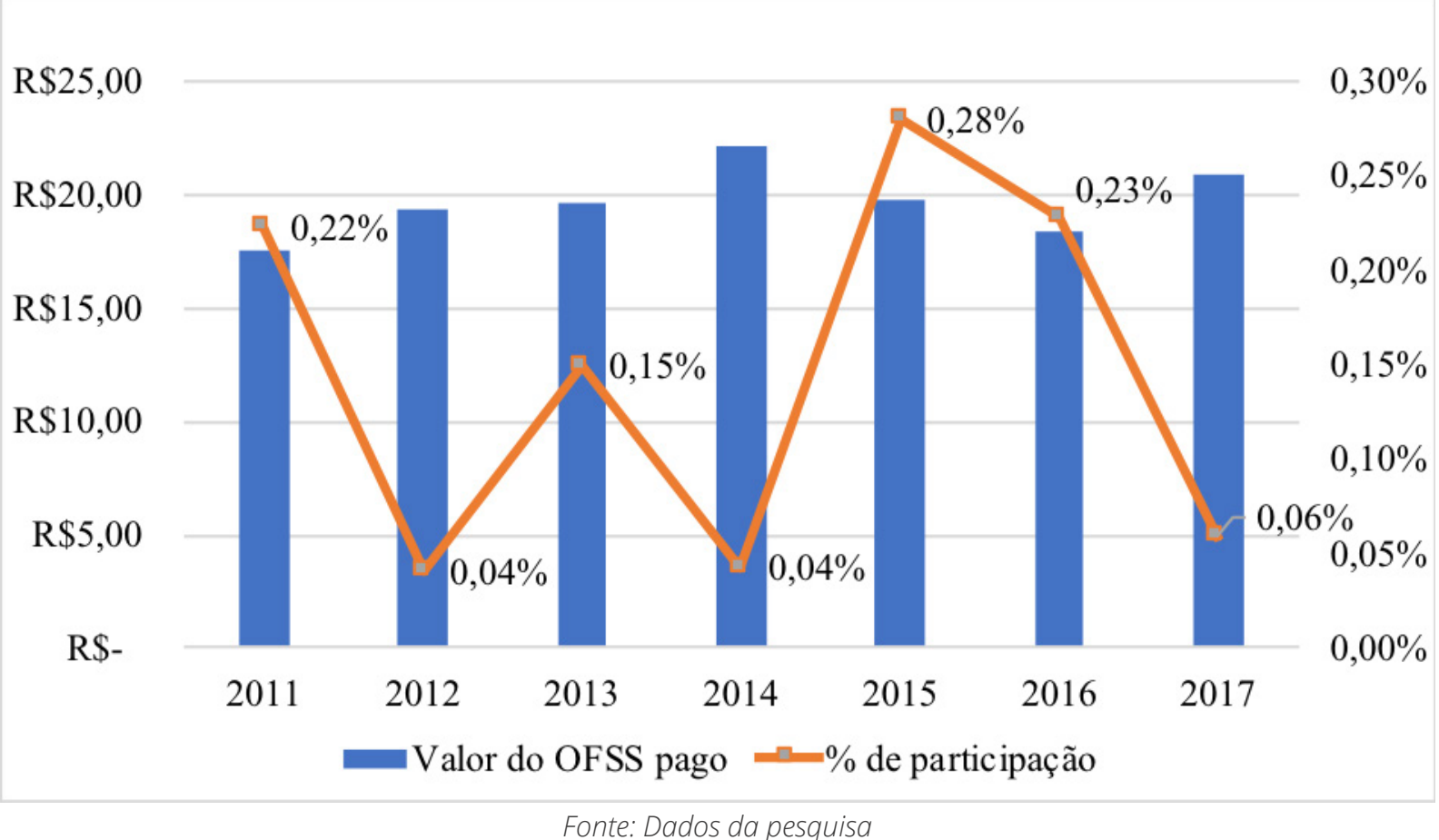

Fonte: Dados da pesquisa

Este dado se assemelha com o apontado por Mascarenhas (2016), que indicava o mesmo movimento instável da participação do Esporte no OFSS do Governo Federal, com menores proporções, variando entre $0,02 \%$ e $0,13 \%$. Portanto, considerando essas informações preliminares, observa-se que o Estado de Goiás investe proporcionalmente mais em esporte se comparado ao Governo Federal.

No entanto, é importante ressaltar que isso não quer dizer que este número indique maior qualidade do investimento, é apenas um apontamento da proporção do montante de investimento. Para aferir essas outras dimensões devem ser incorporados outros indicadores de análise, como o direcionamento dos recursos, realizados no bloco seguinte.

Ademais, esses dados iniciais confirmam o lugar secundário do esporte na agenda governamental, expresso pela baixa participação do setor no orçamento público geral quando comparado a 
O financiamento público estadual do esporte no Estado de Goiás Oromar Augusto dos Santos Nascimento • Fernando Resende Cavalcante • Pedro Fernando Avalone de Athayde • Ari Lazzarotti Filho

outras áreas sociais. Além disso, destaca-se negativamente o comportamento variante dos gastos. Isso porque essa característica pode comprometer a qualidade do atendimento prestado pelos programas e serviços públicos esportivos ao conjunto da população local, bem como engendrar a descontinuidade dessas ações.

Na Figura 3, observou-se a relação percentual entre a Função Desporto e Lazer com o PIB do Estado de Goiás. Percebeu-se continuidade do comportamento instável do financiamento do esporte, que tem irrelevante percentual em relação ao PIB, em que o maior índice gira na casa dos 0,03\% no ano de 2015, um valor baixo e que não contempla o proposto pelas Conferências Nacionais do Esporte I e II, em que o valor ótimo giraria na casa dos 0,4\% de participação do esporte em relação ao PIB (MASCARENHAS, 2016).

Figura 3 - Relação entre os valores pagos à Função Desporto e Lazer e o PIB do Estado de Goiás

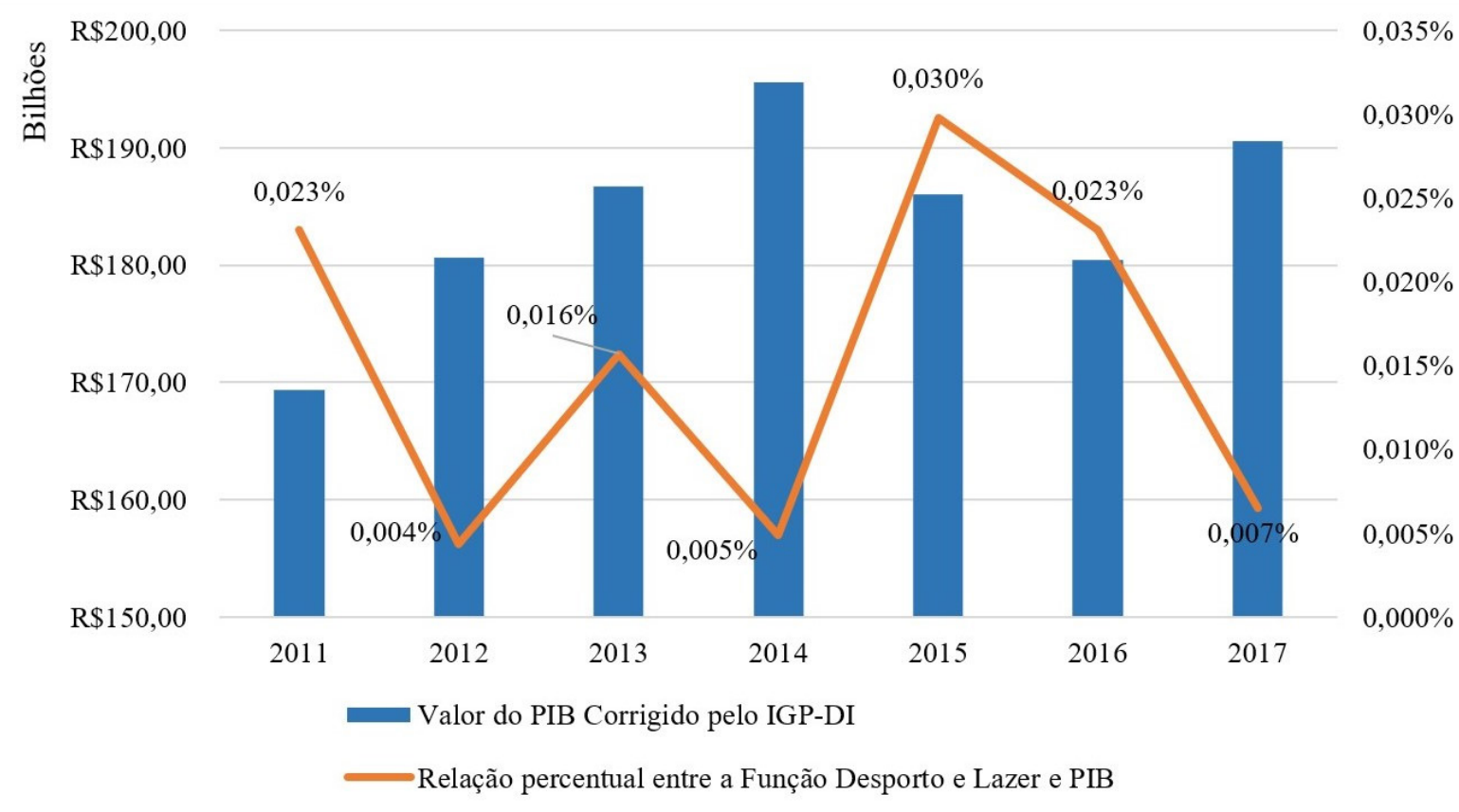

Fonte: Dados da pesquisa

A partir da Função Desporto e Lazer, identificaram-se as subfunções em que esses montantes foram investidos, na Figura 4. 
O financiamento público estadual do esporte no Estado de Goiás Oromar Augusto dos Santos Nascimento • Fernando Resende Cavalcante • Pedro Fernando Avalone de Athayde • Ari Lazzarotti Filho

Ressalta-se que esta função possui 3 subfunções a identificar: Desporto Comunitário, Desporto de Rendimento e Lazer. Além dessas três subfunções, outras quatro que não pertencem à Função Desporto e Lazer receberam direcionamentos: Custódia e Reintegração Social, Assistência à Criança e ao Adolescente, Infraestrutura Urbana e Administração Geral.

Figura 4 - Valor pago para as subfunções associadas à Função Desporto e Lazer

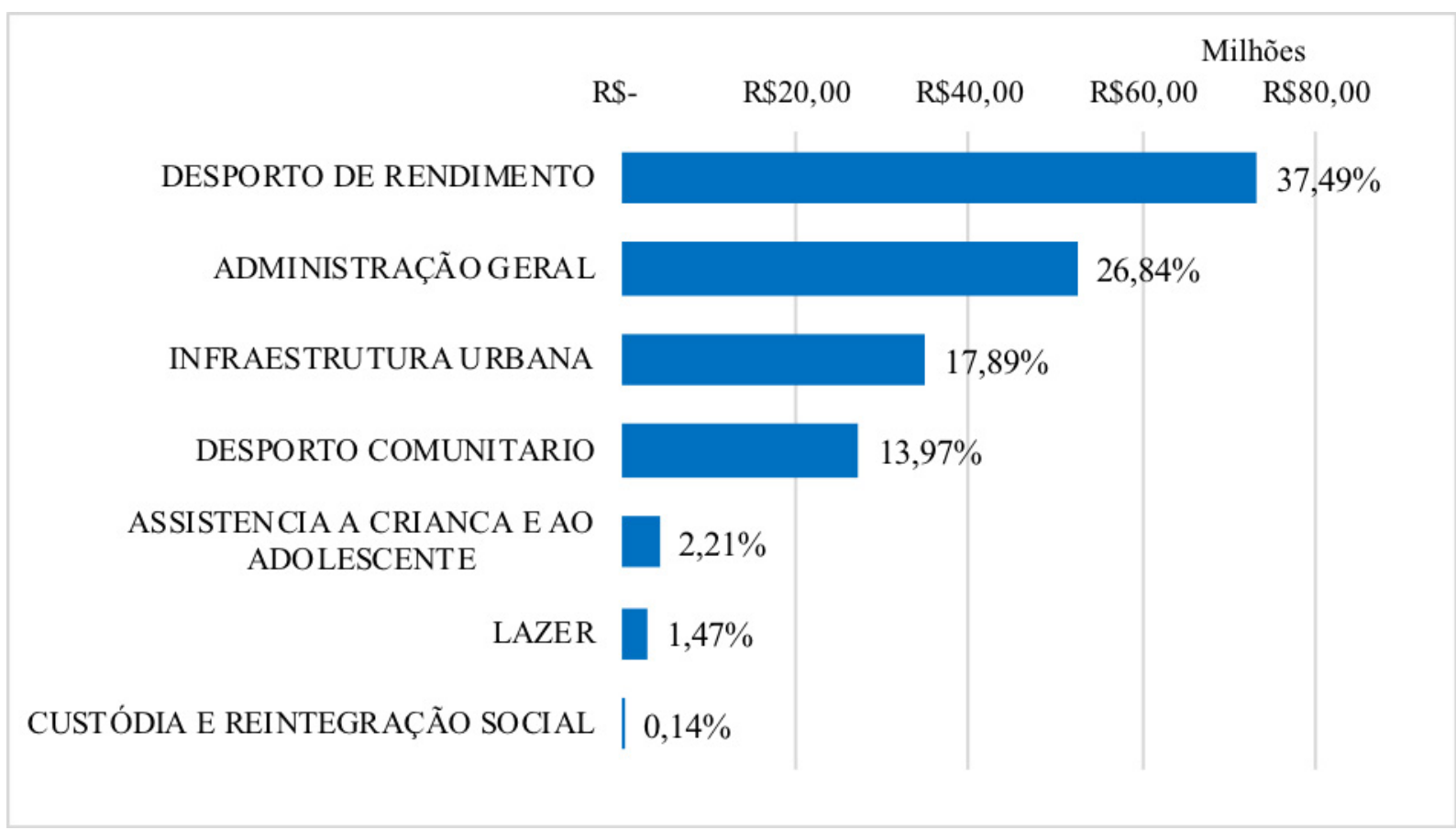

Fonte: Dados da pesquisa

Considerando-se apenas as subfunções, verificou-se um padrão de comportamento semelhante àquele diagnosticado por estudos com abrangência nacional (TEIXEIRA et al., 2017; TEIXEIRA, MATIAS; MASCARENHAS, 2017; ATHAYDE et al., 2015), e estadual (QUINAUD; ALMEIDA, 2018; FURTADO et al., 2016), qual seja: predomínio de gastos no esporte de rendimento. 


\section{Direcionamento dos gastos}

Ao se observar o direcionamento dos gastos, pode-se estabelecer uma relação com a magnitude (os gastos gerais com a Função Desporto e Lazer) no intuito de verificar quais programas e ações estão sendo contemplados pela gestão.

Na Tabela 2 constam todos os programas direcionados ao esporte, localizados nos Projetos Plurianuais de 2009-2011, 20122015 e 2016-2019, e seus respectivos montantes, recuperados a partir dos dados da Execução Orçamentária.

Tabela 1 - Programas destinados ao Esporte no Estado de Goiás no período de 2011 a 2017

\begin{tabular}{lllc}
\hline Programa & $\begin{array}{l}\text { Ano de } \\
\text { vigência }\end{array}$ & Valor pago & $\%$ \\
\hline $\begin{array}{l}\text { PROGRAMA ESPORTE EM AÇÃO - ESPORTE E } \\
\text { LAZER PARA TODOS }\end{array}$ & $\begin{array}{l}2016 \text { a } \\
2017\end{array}$ & $\mathrm{R} \$ 38.061 .692,26$ & $44,83 \%$ \\
\hline PROGRAMA GOIÁS GERAÇÃO OLÍMPICA & 2012 a & $\mathrm{R} \$ 16.931 .974,11$ & $19,95 \%$ \\
\hline PROGRAMA ESPORTE E LAZER PARA TODOS & 2015 & & \\
\hline PROGRAMA GOIÁS GERAÇÃO OLÍMPICA E & $2012 \mathrm{a}$ & $\mathrm{R} \$ 16.652 .658,32$ & $19,62 \%$ \\
PARALÍMPICA & 2016 a & $\mathrm{R} \$ 9.212 .692,42$ & $10,85 \%$ \\
\hline PROGRAMA GOIÁS POTÊNCIA ESPORTIVA & 2017 & $\mathrm{R} \$ 2.555 .419,55$ & $3,01 \%$ \\
\hline PROGRAMA COMUNIDADE ESPORTIVA & 2011 & $\mathrm{R} \$ 1.478 .462,85$ & $1,74 \%$ \\
\hline Total & & $\mathrm{R} \$ 84.892 .899,51$ & $100 \%$ \\
\hline
\end{tabular}

Fonte: Dados da pesquisa

Destacam-se dois aspectos nos programas analisados. O primeiro é a continuidade desses programas, uma vez que o Programa Esporte e Lazer para Todos faz parte do Plano Plurianual 20122015 e o Programa Esporte em Ação - Esporte e lazer para todos faz parte do Plano Plurianual 2016-2019. Antes deles, no Projeto Plurianual 2008-2011, havia o Programa Comunidade Esportiva, que tinha descrição e objetivos semelhantes aos dois progra- 
O financiamento público estadual do esporte no Estado de Goiás Oromar Augusto dos Santos Nascimento • Fernando Resende Cavalcante • Pedro Fernando Avalone de Athayde • Ari Lazzarotti Filho

mas supracitados. O mesmo acontece com o Programa Goiás Potência Esportiva, que constava no Plano Plurianual 2008-2011, o Programa Goiás Geração Olímpica, que consta no Plano Plurianual 2012-2015 e o Programa Goiás Geração Olímpica e Paralímpica, que consta no Plano Plurianual 2016-2019. Pode-se inferir que um programa é a continuidade do outro, visto que todos acontecem na sequência dos mandatos do Governador Marconi Perillo.

O segundo aspecto é a distribuição dos gastos nos programas, que reagrupados a partir da sua centralidade, foram denominados como programas com foco em esporte de participação (Programa Esporte em Ação - Esporte e Lazer Para Todos, Programa Esporte e Lazer Para Todos, Programa Comunidade Esportiva) e programas com foco em esporte de rendimento (Programa Goiás Geração Olímpica, Programa Goiás Geração Olímpica e Paralímpica, Programa Goiás Potência Esportiva).

Nesse sentido, percebeu-se que os direcionamentos ao esporte de participação foram predominantes, com $66,19 \%$ dos recursos direcionados no período. Este dado difere do que se encontrou ao analisar as subfunções, que indicavam predominância dos gastos com o esporte de rendimento.

Percebe-se que os programas acima seguem a continuidade da gestão Perillo, o que explica a manutenção da descrição e objetivo dos programas. Porém, as ações desenvolvidas em cada programa não são necessariamente contínuas, havendo divergências nos investimentos. Para esclarecer essa situação, verticalizou-se a análise sobre as Ações informadas nas planilhas, pois estas são a maior verticalização possível dentro dos dados. Encontrou-se 21 ações no período de 2011 a 2017, que tinham direcionamentos distintos e alcançavam diferentes setores sociais. Elas foram agrupadas segundo sua centralidade e estão expostas no Quadro 1. 
O financiamento público estadual do esporte no Estado de Goiás Oromar Augusto dos Santos Nascimento • Fernando Resende Cavalcante • Pedro Fernando Avalone de Athayde • Ari Lazzarotti Filho

Quadro 1 - Ações destinadas ao esporte no Estado de Goiás no período de 2011 a 2017

\begin{tabular}{|c|c|}
\hline Ação Agrupada & Ação \\
\hline \multirow{5}{*}{$\begin{array}{l}\text { Construção e } \\
\text { manutenção de espaços e } \\
\text { equipamentos esportivos }\end{array}$} & Construção, reforma e ampliação de espaços esportivos \\
\hline & $\begin{array}{l}\text { Estádios, campos, quadras e ginásios (construção/reforma/ } \\
\text { manutenção) }\end{array}$ \\
\hline & $\begin{array}{l}\text { Autódromo internacional de Goiânia (construção/reforma/ } \\
\text { manutenção) }\end{array}$ \\
\hline & Construção e manutenção do Centro de Excelência \\
\hline & $\begin{array}{l}\text { Construção e manutenção, reforma e operacionalização do } \\
\text { Centro de Excelência do Esporte e outras }\end{array}$ \\
\hline \multirow{2}{*}{$\begin{array}{l}\text { Direcionamentos aos } \\
\text { municípios }\end{array}$} & Esporte junto aos municípios \\
\hline & Projetos municipais de desportos \\
\hline \multirow{5}{*}{$\begin{array}{l}\text { Fomento ao esporte de } \\
\text { alto rendimento }\end{array}$} & $\begin{array}{l}\text { Apoio financ. p/ prom. e patrocínios a atletas e eventos esportivos } \\
\text { prof. e amador e doação de mat. esportivos }\end{array}$ \\
\hline & Concessão de incentivo ao atleta de rendimento - Pró-atleta \\
\hline & Promoção e patrocínio a atletas e eventos esportivos \\
\hline & Pró-atleta \\
\hline & $\begin{array}{l}\text { Promoção e patrocínio a eventos, atletas e instituições de prática } \\
\text { e administração esportiva }\end{array}$ \\
\hline \multirow{2}{*}{ Iniciação esportiva } & Iniciação esportiva \\
\hline & Iniciação esportiva e esporte comunitário \\
\hline \multirow{2}{*}{$\begin{array}{l}\text { Fomento e participação } \\
\text { em jogos escolares e } \\
\text { universitários }\end{array}$} & Jogos universitários brasileiros \\
\hline & Jogos abertos de Goiás \\
\hline \multirow{3}{*}{$\begin{array}{l}\text { Fomento do esporte de } \\
\text { participação e de lazer }\end{array}$} & Eventos recreativos \\
\hline & Navegar \\
\hline & Promoção da prática de esportes e lazer para todos \\
\hline \multirow{2}{*}{$\begin{array}{l}\text { Projeto Pintando a } \\
\text { liberdade }\end{array}$} & Projeto pintando a liberdade - (produção de material esportivo) \\
\hline & Produção de material esportivo/projeto pintando a liberdade \\
\hline
\end{tabular}

Fonte: Dados da pesquisa

Dessas ações, destaca-se que uma parcela significativa é voltada para a construção, manutenção e reforma de espaços e equipamentos esportivos, que concentram o maior montante dos valores gastos com o esporte (40\%), conforme exposto na Figura 5. 
O financiamento público estadual do esporte no Estado de Goiás

Oromar Augusto dos Santos Nascimento • Fernando Resende Cavalcante • Pedro Fernando Avalone de Athayde • Ari Lazzarotti Filho

Figura 5 - Valor pago a ações destinadas ao esporte, agrupadas segundo sua centralidade

$$
\begin{array}{ccccc} 
& & \multicolumn{2}{c}{\text { Milhões }} \\
\mathrm{R} \$- & \mathrm{R} \$ 10,00 & \mathrm{R} \$ 20,00 & \mathrm{R} \$ 30,00 \quad \mathrm{R} \$ 40,00
\end{array}
$$

Construção e manutenção de espaços e equipamentos esportivos

Direcionamentos aos municípios

Fomento ao esporte de alto rendimento

Iniciação esportiva

Fomento e participação em jogos escolares e universitários

Fomento do esporte de participação e de lazer

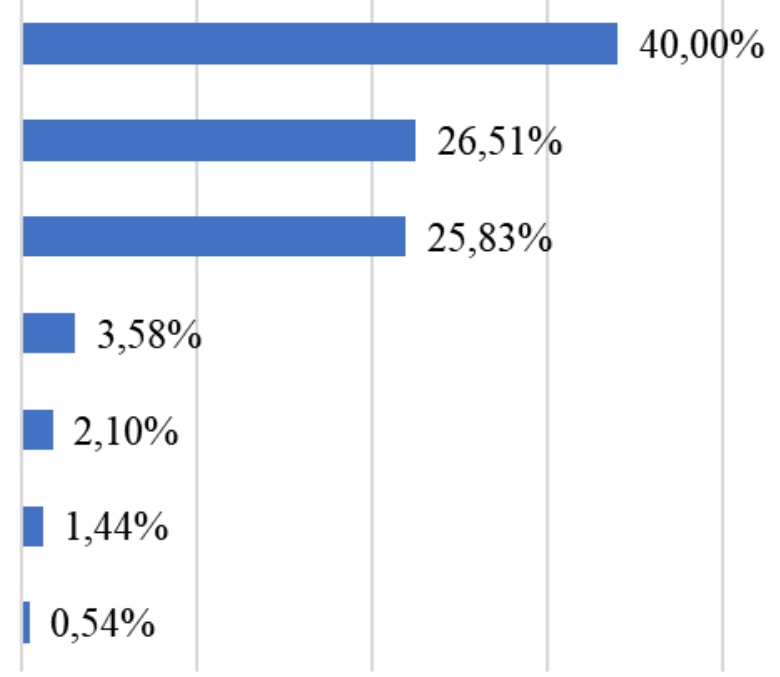

Projeto Pintando a liberdade | $0,54 \%$

Diante dos dados apresentados, percebe-se que as ações destinadas ao esporte têm frentes específicas de atuação, como a manutenção e construção de espaços e instalações esportivas, descentralização de recursos para os municípios e o fomento de eventos e pagamento de bolsas. Destaca-se nesse cenário, a grande quantidade de verbas utilizadas na construção, manutenção, reforma e ampliação de espaços destinados ao esporte, que somaram $\mathrm{R} \$ 33.958 .609,05$, correspondendo a $40,00 \%$ do montante gasto em esporte no período.

Pode-se explicar essa soma nas ações destinadas às grandes obras em que o Estado se apresenta como principal financiador. Essa situação evidencia a prioridade do Governo Estadual em investimentos na infraestrutura esportiva, algo visto no ciclo de Megaeventos Esportivos e apontado nos trabalhos de Quinaud e Almeida (2018), e Mascarenhas (2016, 2012). 
O financiamento público estadual do esporte no Estado de Goiás Oromar Augusto dos Santos Nascimento • Fernando Resende Cavalcante • Pedro Fernando Avalone de Athayde • Ari Lazzarotti Filho

Mascarenhas (2016) destaca como aspecto negativo a vinculação entre os investimentos em infraestrutura esportiva e os recursos advindos de emendas parlamentares, uma vez que essa relação sinaliza para uma política organizada a partir de interesses clientelistas.

Ocorre que o clientelismo opera como uma troca pela qual os titulares de cargos políticos, neste caso, os parlamentares, regulam a concessão de recursos obtidos a partir de sua função pública em busca de apoio eleitoral. De tal feito, o aparato administrativo do Estado é colocado a serviço do benefício privado. De um lado, o "patrão", representado aqui pela figura do parlamentar, dotado de poder para influir seus "funcionários" - leia-se funcionários públicos - na destinação dos recursos públicos, toma decisões a fim de favorecer seus "clientes", ou seja, sua base eleitoral (MASCARENHAS, 2016, p. 975).

Observando-se os dados da Figura 5, é válido refletir se essa orientação clientelista não estaria no cerne de outra ação de destaque, o "esporte junto aos municípios"; ação que recebeu o segundo maior montante de recursos, $\mathrm{R} \$ 22.509 .063,26$. Nesse sentido, fica aberta a perspectiva de um estudo futuro com análise aprofundada das fontes (origem) de recursos para o esporte do Estado de Goiás, especialmente aqueles referentes à infraestrutura.

Ao mesmo tempo, ressalta-se que os gastos com a infraestrutura esportiva estão dispersos dentro dos programas vinculados nas três subfunções (rendimento, educacional e participação) e a subfunção de infraestrutura. Entretanto, é importante observar que algumas ações ainda que se vinculem a programas que teoricamente estariam situados na subfunção de Desporto de participação, parecem atender mais diretamente ao esporte de rendimento.

Esse seria o caso, por exemplo, das ações que envolvem a construção/reforma/manutenção do Autódromo Internacional de Goiânia ou de estádios, campos, quadras e ginásios dentro 
O financiamento público estadual do esporte no Estado de Goiás Oromar Augusto dos Santos Nascimento • Fernando Resende Cavalcante • Pedro Fernando Avalone de Athayde • Ari Lazzarotti Filho

do Programa Esporte e Lazer para Todos. Esse seria um dos elementos capazes de explicar a contradição apontada anteriormente entre os dados apresentados nas Figuras 4 (gastos significativos direcionados à subfunção Desporto de Rendimento) e Tabela 2 (Programa Esporte em Ação - Esporte e Lazer para Todos com $44,83 \%$ dos gastos).

Tal cenário vai ao encontro da fase do Capitalismo Tardio e as funções do Estado, apresentadas por Mandel (1982). O Estado passa a socializar parte dos custos e riscos de produção, com orçamento para investimentos em setores essenciais para o desenvolvimento econômico, sendo a construção civil um desses setores. A ampliação do campo de intervenção do Estado cria condições para que ele articule interesses econômicos aos interesses políticos. Dessa maneira, além de manter as relações de classe, o Estado tardio serve como aparato de crescimento de capital, estabelecendo contratos com grupos empresariais e atendendo a interesses específicos, em sua ação direta no setor produtivo ou na criação e alteração de leis e políticas públicas (MANDEL, 1982).

Em última análise, o financiamento público estadual do Esporte em Goiás tem características semelhantes ao que acontece na esfera Federal, com instabilidade de investimentos e pequena participação em relação ao OFSS e ao PIB.

Do montante destinado à Função Desporto e Lazer $R \$ 195.443 .809,07$, conseguiu-se identificar $R \$ 84.892 .899,51$ destinados a programas e suas respectivas ações. Essa diferença pode ser explicada pelo fato de que nem todo orçamento destinado à Função Desporto e Lazer pode ter sido gasto com Programas Esportivos, podendo ser direcionado para outros programas, de outras áreas, que dialoguem com o esporte, o que exigiria uma análise orçamentária completa do período, inviável para este trabalho e o objetivo proposto. 


\section{Considerações finas}

O investimento em esporte no Estado de Goiás durante o período analisado se mostrou instável, alternando entre vales e picos de investimento, com pouca participação em relação ao OFSS e ao PIB. Apesar de haver certa continuidade dos programas esportivos, suas ações não possuem tal característica, uma vez que os montantes destinados aos programas esportivos se aproximaram do esporte de participação. Já as ações tiveram seus montantes em grande parte direcionados aos gastos em infraestrutura, já que o Estado custeou grandes obras, se colocou enquanto agente financiador da economia e garantiu a manutenção da cadeia produtiva.

Esses achados vão de encontro à literatura apresentada e evidenciam que o esporte vem recebendo atenção do poder público de forma pontual, com um aumento do fluxo de investimentos associado aos grandes eventos esportivos, que não se reverteram em fomento ao acesso ao esporte por parte da população.

Destaca-se que este é o primeiro exercício de imersão nos dados coletados e que é uma tentativa de criação de um panorama do financiamento do esporte em Goiás, portanto tem como limite não explorar as relações entre as ações e programas, além de não ser possível identificar onde efetivamente se materializaram os gastos, visto que a plataforma Goiás Transparente é uma ferramenta que não fornece esses dados. Outro limite diz respeito a não identificação das fontes dos recursos. Tais limites se mostram como novas possibilidades de estudo, uma vez que analisar como esses gastos apresentados se materializaram pode ampliar a compreensão do funcionamento das políticas esportivas no Estado de Goiás.

Este trabalho trouxe importantes contribuições para os estudos das políticas esportivas em Goiás e contribui para a exposição e transparência dos gastos públicos, algo essencial para o fortalecimento da democracia e do planejamento social. 
O financiamento público estadual do esporte no Estado de Goiás

Oromar Augusto dos Santos Nascimento • Fernando Resende Cavalcante • Pedro Fernando Avalone de Athayde • Ari Lazzarotti Filho

\section{Referências}

ATHAYDE, P. F. A. et al. Primeiras aproximações de uma análise do financiamento da política nacional de esporte e lazer no governo Lula. In: Wagner Barbosa Matias; Pedro Fernando Athayde; Fernando Mascarenhas. (Org.). Política de esporte nos anos Lula e Dilma. 1 ed. Brasília: Thesaurus, 2015, v. 1, p. 117-140. ATHAYDE, P. F. A. O "lugar do social" na política de esporte do governo Lula. In: Wagner Barbosa Matias; Pedro Fernando Athayde; Fernando Mascarenhas. (Org.). Política de esporte nos anos Lula e Dilma. 1 ed. Brasília: Thesaurus, 2015, v. 1, p. 187-210. BOITO JUNIOR, A. As bases políticas do neodesenvolvimentismo. (Trabalho apresentado na edição de 2012 do Fórum Econômico da FGV / São Paulo).

BOSCHETTI, I. S. Avaliação de políticas, programas e projetos sociais. In: CONSELHO FEDERAL DE SERVIÇO SOCIAL (org.). Serviço social: direitos sociais e competências profissionais. Brasília: CFESS, 2009.

DINIZ, R. S.; SILVA, L. P. O ICMS esportivo e o financiamento das políticas municipais de esporte em Minas Gerais. Movimento, Porto Alegre v. 22, n. 4, p. 1223, out./dez. 2016. Disponível em: https://seer.ufrgs.br/Movimento/article/view/64264/39738. Acesso em: 02 nov. 2018.

FURTADO, S. et al. O financiamento do esporte em Santa Catarina: o caso do FUNDESPORTE nos anos de 2011 e 2012. Motrivivência, Florianópolis, v. 28, n. 47, p. 145, 25 maio 2016. Disponível em: https://periodicos.ufsc.br/index.php/motrivivencia/article/view/2175-8042.2016v28n47p145. Acesso em: 02 nov. 2018.

MASCARENHAS, F. Megaeventos esportivos e Educação Física: alerta de tsunami. Movimento, Porto Alegre, v. 18, n. 1 p. 39-67, jan./mar. 2012. Disponível em: http://seer.ufrgs.br/index.php/ Movimento/article/view/25260/17340. Acesso em: 29 jan. 2019. 
O financiamento público estadual do esporte no Estado de Goiás

Oromar Augusto dos Santos Nascimento • Fernando Resende Cavalcante • Pedro Fernando Avalone de Athayde • Ari Lazzarotti Filho

MASCARENHAS, F. O orçamento do esporte: aspectos da atuação estatal de FHC a Dilma. Revista Brasileira de Educação Física e Esporte, São Paulo, v. 30, n. 4, out.-dez. 2016. Disponível em: http://www.scielo.br/pdf/rbefe/v30n4/1807-5509-rbefe-30-04-0963.pdf. Acesso em: 08 nov. 2018.

MATIAS, W. B. et al. A Lei de Incentivo Fiscal e o (não) direito ao esporte no Brasil. Movimento, Porto Alegre, p. 95-110, jan./mar. 2015. Disponível em: http://seer.ufrgs.br/index.php/Movimento/ article/view/46419. Acesso em: 28 nov. 2017.

MINAYO, M. C. S. Pesquisa social: teoria método e criatividade. 28. ed. Petrópolis: Vozes, 2009.

QUINAUD, R. T.; ALMEIDA, B. S. Financiamento público no esporte: os repasses do Estado de Santa Catarina para projetos na mesorregião grande Florianópolis (2007-2014). Pensar a Prática, Goiânia, v. 21, n. 2, abr./jun. 2018. Disponível em: https://www. revistas.ufg.br/fef/article/view/46064. Acesso em: 02 nov. 2018 STAREPRAVO, F. A. et al. Esporte universitário brasileiro: uma leitura a partir de suas relações com o Estado. Revista Brasileira de Ciências do Esporte, Campinas, v. 31, n. 3, 4 mai. 2010. Disponível em: http://www.scielo.br/pdf/rbce/v31n3/v31n3a09. pdf. Acesso em: 02 nov. 2018.

TEIXEIRA, M. R. et al. O programa bolsa atleta no contexto esportivo nacional. Motrivivência, Florianópolis, v. 29, n. 0, p. 92-109, dez. 2017. Disponível em: https://periodicos.ufsc.br/index.php/ motrivivencia/article/view/2175-8042.2017v29nespp92. Acesso em: 02 nov. 2018.

TEIXEIRA, M. R.; MATIAS, W. B.; MASCARENHAS, F. O esporte olímpico no Brasil: recursos financeiros disponibilizados para Olimpíadas Londres 2012. Revista Brasileira de Ciências do Esporte, v. 39, n. 3, p. 284-290, jul./set. 2017. Disponível em: http://www.scielo.br/pdf/rbce/v39n3/0101-3289-rbce-39-03-0284. pdf. Acesso em: 02 nov. 2018. 
O financiamento público estadual do esporte no Estado de Goiás

Oromar Augusto dos Santos Nascimento • Fernando Resende Cavalcante • Pedro Fernando Avalone de Athayde • Ari Lazzarotti Filho

\section{Financiamento}

A presente pesquisa foi financiada pela Coordenação de Aperfeiçoamento de Pessoal de Nível Superior (CAPES)

\section{Publisher}

Universidade Federal de Goiás. Faculdade de Educação Física e Dança. Publicação no Portal de Periódicos UFG. As ideias expressadas neste artigo são de responsabilidade de seus autores, não representando, necessariamente, a opinião dos editores ou da universidade. 